Available online at GSC Online Press Directory

GSC Biological and Pharmaceutical Sciences

e-ISSN: 2581-3250, CODEN (USA): GBPSC2

Journal homepage: https://www.gsconlinepress.com/journals/gscbps

(RESEARCH ARTICLE)

\title{
Anemia among pregnant women in the northwest of Libya
}

\author{
Khaled Ali Alawaini 1, *, Sara Abulgasem Altabeb 2, Samah Said Alalwe 2, Malak Yhya Alazabe 2, Wesal Salih \\ Yaghoub ${ }^{2}$ and Tayri Mohamed Sarika ${ }^{2}$
}

${ }^{1}$ PhD student in biochemistry department, Memorial Canada.

${ }^{2}$ Higher institute of science and medical technology/Jado.

Publication history: Received on 08 September 2020; revised on 23 September 2020; accepted on 25 September 2020

Article DOI: https://doi.org/10.30574/gscbps.2020.12.3.0293

\begin{abstract}
Anemia is a significant public health problem worldwide, especially in developing countries, leading to mortality and morbidity in women and children. Anemia may cause low birth weight and premature birth, and increase the risk of maternal mortality due to bleeding and other delivery complications. However, iron deficiency is the most cause of anemia. Therefore, our primary objective is to estimate the prevalence of anemia in the northwest part of Libya. A hundred pregnant women participated in this study. Hemoglobin (Hb) level, mean corpuscular volume (MCV), and iron concentration were measured. In addition to that, a questionnaire was completed to collect information such as age, education, medication, and whether the participants drink tea or coffee after a meal. The level of anemia was very high; it was found that $72 \%$ of pregnant women. Out of this, $66.6 \%, 30.5 \%$, and $2.9 \%$ were mild, moderate, and severe anemia, respectively.
\end{abstract}

Keywords: Anemia; Hb; MCV; Pregnant

\section{Introduction}

Anemia is defined as a low level of Hb below: $13.0 \mathrm{~g} / \mathrm{dL}$ in adult men, below $12.0 \mathrm{~g} / \mathrm{dL}$ in women (1), and below 11.0 $\mathrm{g} / \mathrm{dL}$ in pregnant women $(9,1)$. However, Hb levels may vary according to age and race. Furthermore, lifestyle also impacts $\mathrm{Hb}$ levels (cigarettes, food habits) (2). In addition to that, places of higher altitudes may affect the level of hemoglobin (2). However, hypoxia leads to an increase in red blood cell count (2). Anemia is affects $25 \%$ of the world's population, and iron deficiency (IDA) is the most cause (1). In addition to IDA, anemia could be due to chronic infections, particularly malaria (3), hereditary hemoglobinopathies, and other vitamin deficiencies, especially folic acid (4). In developing countries, anemia's prevalence is 3 to 4 time's great than in industrial countries (5). People with low hemoglobin, low mean corpuscular volume (MCV), or low mean corpuscular hemoglobin (MCH) could be suffering from anemia due to iron deficiency (6). The prevalence of iron deficiency anemia worldwide is high, affecting the general health and wellbeing of 2 billion people (5), whereas 3.5 billion people in developing countries are estimated to suffer from anemia (5). Furthermore, anemia is considered a significant public health problem that can lead to mortality and morbidity in women and children (7). Anemia may cause low birth weight and premature birth, as well as increase the risk of maternal mortality due to bleeding and other delivery complications (8). Anemia is very prevalent in Africa; $57.1 \%$ of pregnant women were found to be anemic, more specifically, $62.7 \%$ of pregnant women in Ethiopia (9). The definitive diagnosis of iron deficiency depended on low serum iron and low level of transferrin. However, serum ferritin can also be reduced in liver disease, inflammation, or cancer disease (10). Therefore, to treat and solve anemia's high prevalence, especially in developing countries, and despite many efforts, more attention and studies should be created. So, our study's main objective is to estimate anemia's prevalence in the northwest of Libya.

\footnotetext{
* Corresponding author: Khaled Ali Alawaini

PhD student in biochemistry department, Memorial Canada..
} 


\subsection{Objective}

To determine the prevalence of anemia, especially IDA, among pregnant women who attended to Jado hospital in Libya.

\section{Methods}

A hundred randomly selected pregnant women of reproductive age (19-49 years) with a mean age of 35.2 participated in this study. All attended Jado hospital, which is located at a high altitude, about 1000-m above the sea level; it is about $200 \mathrm{~km}$ away from the capital city of Libya to the northwest. The study was conducted in 2013 from May 2, Jun 20. However, during their usual medical checkup, $5 \mathrm{ml}$ of venous blood was collected in an EDTA tube for complete blood count (CBC) and a plane tube to separate serum to test iron levels. However, due to limited time in this study and other reasons, we only measured $\mathrm{Hb}, \mathrm{MCV}$, and iron results. In addition to that, a questionnaire asked for information from patients about a name, age, residence, chronic diseases, education, a period of pregnancy, and tea or coffee drinking to assess the risk factors. Types of anemia were classified as:

Mild anemia 9.0-10.9g/dl

Severe anemia $<7.0 \mathrm{~g} / \mathrm{dL}$

Moderate anemia 7.0-8.9g/dL $(11,12)$

References were used to define the normal ranges for $\mathrm{MCV}>76.0-96.0 \mathrm{fl} ; \mathrm{Hb}>10.9 \mathrm{~g} / \mathrm{dl}$.

\section{Results}

Table 1 Distribution of pregnant women according to the address

\begin{tabular}{|l|l|}
\hline Name of the city & Number of cases \\
\hline Jado & 37 \\
\hline Rigban & 29 \\
\hline Alrhebat & 31 \\
\hline Alzintan & 3 \\
\hline Total & 100 \\
\hline
\end{tabular}

Table 2 Prevalence of anemia among pregnant women.

\begin{tabular}{|l|l|l|}
\hline Number of cases & Normal & Anemic \\
\hline 100 & 28 & 72 \\
\hline
\end{tabular}

Out of 100 pregnant women, 72 showed a low level of $\mathrm{Hb}, \mathrm{MCV}$, and iron concentration. As a result, the level of anemia was very high.

Table 3 Distribution of anemia according to their age groups.

\begin{tabular}{|l|l|l|l|}
\hline Age group & Number of cases & Percentage\% & Average Hb \\
\hline $19-28$ & 43 & $43 \%$ & 10.5 \\
\hline $29-38$ & 52 & $52 \%$ & 9.1 \\
\hline $39-49$ & 5 & $5 \%$ & 9.9 \\
\hline
\end{tabular}


Table 4 Age groups wise mean of MCV.

\begin{tabular}{|l|l|l|l|}
\hline Age group & Number of cases & Percentage $\%$ & Average MCV \\
\hline $19-28$ & 43 & $43 \%$ & $81 \%$ \\
\hline $29-38$ & 52 & $52 \%$ & $72.1 \%$ \\
\hline $39-49$ & 5 & $5 \%$ & $90 \%$ \\
\hline
\end{tabular}

Table 5 Anemia according to gestational age.

\begin{tabular}{|l|l|l|l|}
\hline Month & Number of cases & Percentage\% & Average $\mathbf{H b}$ g/dl \\
\hline $1-3$ & 17 & 17 & 10.7 \\
\hline $3-6$ & 23 & 23 & 10.1 \\
\hline $6-9$ & 60 & 60 & 9.2 \\
\hline
\end{tabular}

Clearly that the third trimester (6-9mo) showed a lower level of mean hemoglobin concentration when compared with the other months.

Table 6 Comparison of healthy pregnant women finding and anemic pregnant women.

\begin{tabular}{|l|l|l|l|l|l|}
\hline \multicolumn{2}{|l|}{ Healthy subjects } & \multicolumn{3}{l|}{ Anemic patients } \\
\hline Number of normal cases & Test & Average & Cases number & & Average \\
\hline 28 & Hb & 11.9 & 72 & Hb & 9.5 \\
\hline 28 & MCV & 84.8 & 72 & MCV & 72 \\
\hline 28 & Iron & 77 & 72 & Iron & 59.7 \\
\hline
\end{tabular}

Anemia was seen in $72 \%$ of pregnant women when compared with non-anemia pregnant women as in table 6 (Hb concentration $9.5 \mathrm{~g} / \mathrm{d}$ vs11.9g/dl).

Table 7 Classification of Anemia according to the severity.

\begin{tabular}{|l|l|l|}
\hline Number of normal cases & Type of Anemia & Percentage\% \\
\hline 48 & Mild & 66.6 \\
\hline 22 & Moderate & 30.5 \\
\hline 2 & Sever & 2.9 \\
\hline Total of 72 & & $100 \%$ \\
\hline
\end{tabular}

Most anemic patients were suffering from mild anemia (66.6) when compared with moderate and severe anemia.

Table 8 Socio-demographic characteristics of the study population.

\begin{tabular}{|l|l|l|l|}
\hline & Cases number (Yes) & Cases number (No) & Total \\
\hline Education & 93 & 7 & 100 \\
\hline Bleeding & 60 & 40 & 100 \\
\hline Medications & 10 & 90 & 100 \\
\hline coffee or tea after a meal & 58 & 42 & 100 \\
\hline
\end{tabular}


In this study, most anemic patients were educated (93\%) and 60\% suffered from bleeding, whereas 58\% always drank coffee or tea after a meal. Iron absorption could be decreased when drinking coffee immediately after a meal, as many studies have demonstrated.

\section{Discussion}

Anemia, especially in pregnant women, is a significant problem in developing countries not only to the mother but to the baby's health as well. In this study, the mean $\mathrm{Hb}$ concentration was $9.5 \mathrm{~g} / \mathrm{d}$ in anemic patients. The results showed a high prevalence of anemic patients among pregnant women, $72 \%$ out of 100 pregnant women; this high number could reflect that $90 \%$ of them did not take iron supplements or folic acid, as shown in Table 8 , whereas 58\% of pregnant women always drank coffee or tea after a meal. Iron absorption could be decreased when drinking coffee immediately after a meal, as many studies have demonstrated. Anemia levels were higher in our study than in Elzahaf and Omar's study (11) in the northeast of Libya (72\% vs. 54.6\%); both studies were carried out in cities located at a high level above the sea. Anemia was found more prevalent in the age group between 29 to 38 years old when compared with the other groups, as shown by their Hb and MCV levels, as in table 3 and 4. Moreover, the prevalence of anemia was high during the third trimester of pregnancy, as the concentration of $\mathrm{Hb}$ was $9.2 \% \mathrm{~g} / \mathrm{dl}$. Worldwide, $41.8 \%$ of pregnant women are anemic compared to $30.2 \%$ of non-pregnant women; the most severely affected areas are South-East Asia (48.2\%) and Africa (57.1\%) (12). We found that the prevalence of anemia was very high in this study; however, $66.6 \%$ of participants had mild anemia (with Hb levels below ranged from(9-10.9g/dl), 30.5\% had moderate Anemia (Hb levels of 7.0$8.9 \mathrm{~g} / \mathrm{dl})$. Conversely, another study in Libya mentioned that severities of anemia among the anemic fraction (47\%) of the studied population; were distributed as follows: $14.2 \%$ had mild anemia, $31.8 \%$ had moderate anemia, only $1 \%$ had severe anemia (13). In the northwest of Libya also, the prevalence of mild, moderate, and severe anemia was observed as $44.5 \%, 7.6 \%$, and $2.5 \%$, respectively (11). In Gondar, in the northwest of Ethiopia, anemia was even more prevalent, with $(64 \%$ for the) mild type, $(30 \%)$ for the moderate, and (6\%) for severe (9). In Nigeria, it was found that $54.5 \%$ of pregnant women were anemic (13). Iron deficiency anemia is due to high iron demand. In developing countries, $52 \%$ of pregnant women are affected (14). In Egypt, IDA prevalence was 51.3\% (1267 of 2470); IDA affects about one in every two pregnant women in rural districts (15). According to our study, $72 \%$ of cases had low iron (59.7mcg/dl) and MCV (72fl). Out of 100 pregnant women, $60 \%$ had bleeding. However, this could reflect a high rate of anemia. Future analysis, $\mathrm{Hb}$ concentrations, and other physiological parameters include a full picture of complete blood count and blood smear. In addition to that, serum transferrin and ferritin would prove useful; however, the diagnosis of iron deficiency depended on low serum iron and low level of transferrin, thus could be since serum ferritin can be reduced in liver disease, inflammation, or cancer disease (10).

\section{Conclusion}

The prevalence of anemia, probably IDA, was reported very high among pregnant women in Libya. Therefore, more attention and regular medical checkups and folic acid intake and iron supplements should be considered.

\section{Compliance with ethical standards}

\section{Acknowledgments}

We want to thank all the staff and patients at Jado hospital for their helping and support.

\section{Disclosure of conflict of interest}

The authors declare no conflict of interest.

\section{Statement of informed consent}

Patients in this study gave their informed consent.

\section{References}

[1] Jimenez K, Dabsch SK, Gasche C. Gastroenterology \& hepatology. Management of iron deficiency anemia 2015; 11(4): 241-250.

[2] Sharma AJ, Addo OY, Mei Z, Suchdev PS. Reexamination of hemoglobin adjustments to define anemia: altitude and smoking. Ann N Y Acad Sci. 2019; 1450 (1): 190-203. 
[3] Wemakor A, Prevalence and determinants of anemia in pregnant women receiving antenatal care at a tertiary referral hospital in Northern Ghana. Wemakor BMC Pregnancy and Childbirth.2019; (2019) 19:495.

[4] Pavord S, Daru J, Prasannan N, Robinson S, Stanworth S, Girling J. UK guidelines on the management of iron deficiency in pregnancy. British journal of hematology. 2020; 188: 819-830.

[5] Foo LH, Khor GL, Tee ES, Prabakaran D. Iron status and dietary. Iron intake of adolescents from a rural community in Sabah, Malaysia. Asia Pacific J Clin Nutr. 2004; 13 (1): 48-55.

[6] Pasricha SR, Brown SCF, Allen KJ, Gibson PR, McMahon LP, Olynyk JK, Roger SD, Savoia HF, Tampi R, Thomson AR, Wood EM, Robinson KL. Diagnosis and management of iron deficiency anemia: a clinical update. 2010; 193 (9): 525-532.

[7] Chaparro CM, Suchdev PS. Anemia epidemiology, pathophysiology, and etiology in low- and middle-income countries. Ann N Y Acad Sci. 2019; 1450 (1): 15-31.

[8] Rasmussen, K. Is there a causal relationship between iron deficiency or iron-deficiency anemia and weight at birth, length of gestation, and perinatal mortality? Journal of nutrition. 2001; 131 (2): 590-603.

[9] Melku M, Addis Z, Alem M, Enawgaw B. Prevalence and predictors of maternal anemia during pregnancy in Gondar, northwest Ethiopia: An Institutional based cross-sectional study. 2014.

[10] Urrechaga E, Borque L, Escanero JF. Biomarkers of hypochromia: the contemporary assessment of iron status and erythropoiesis Biomed Res Int. 2013.

[11] Elzahaf R and Omar M. Prevalence of anemia among pregnant women in Derna city, International Journal of Community Medicine and Public Health. Int J Community Med Public Health. 2016; 3 (7): 1915-1920.

[12] Ndukwu GU, Dienye PO. Prevalence and socio-demographic factors associated with anemia in pregnancy in a primary health center in Rivers State, Nigeria. Afr J prim health care fam med. 2012; 4(1): 328.

[13] Mazughi I FM, Arebi A MY and Sheri F M. Prevalence of anemia among Libyan pregnant women and its relation to low birth weight.2018; International Journal of academic health and medical research (IJAHMR).2018; (2): 16.

[14] Abu-ouf, NM, Jan MM. The impact of maternal iron deficiency and iron deficiency anemia on a child's health. Saudi med J. 2015; 36(2): 146-149.

[15] Rezk M, Marwan H, Dawood R, Masood A \& Abo-Elnasr M. Prevalence and risk factors of iron-deficiency anemia among pregnant women in rural districts of Menoufia governorate, Egypt. Journal of Obstetrics and gynecology. 2015; 35(7): 663-6. 